\title{
Results of Percutaneous Transluminal Coronary Angioplasty of High-Risk Angulated Stenoses
}

\author{
Stephen G. Ellis, MD, and Eric J. Topol, MD
}

Percutaneous transluminal coronary angioplasty (PTCA) of angulated stenoses has been found in studies using older PTCA equipment to be associated with a heightened risk of procedure-related major ischemic events. To better understand the factors assoclated with procedural risk and to Identify means of lessening that risk, 100 patients, treated sequentially from 1986 to 1989 , who underwent PTCA of stenoses located at $\geq 45^{\circ}$ bends, were characterized for 27 clinical, anatomic and procedural variables. Clinical outcome of angioplasty was related to these variables. In addition, results from 344 consecutive contemporary patients undergoing PTCA of nonangulated lesions were compared to those of the study group. Procedural success was achieved in only $70 \%$ of patients with angulated stenoses, compared with 306 of $344(89 \%)$ nonangulated stenoses, and major ischemic complications (death, bypass surgery or myocardial infarction) occurred in $13 \%$ of patients with angulated stenoses compared with 12 of 344 $(3.5 \%)$ with nonangulated stenoses (both $p$ $<0.001$ ). The presence of associated thrombus, stenosis length $>10 \mathrm{~mm}$ or age $\geq 65$ years led to an even higher risk of major complications (9 of $44=$ $\mathbf{2 0 . 5} \%$ ), whereas highly experienced angioplasty operators and the use of polyethylene terephthalate balloons appeared to decrease risk and increase the Fikelihood of success. PTCA of such stenoses should be undertaken only cautiously and in carefully selected patients.

(Am J Cardiol 1990;66:932-937)

From the Division of Cardiology, Department of Internal Medicine, University of Michigan Medical Center, 1500 East Medical Center Drive, Ann Arbor, Michigan 48109. This study was independently supported by the University of Michigan Division of Cardiology Research Program and Grant HL 38529-03 from the National Institutes of Health, Bethesda, Maryland. No angioplasty equipment manufacturers provided financial support or were privy to the data before the completion of the study. Manuscript received March 20, 1990; revised manuscript received June 7, 1990, and accepted June 8.

Address for reprints: Stephen G. Ellis, MD, University of Michigan Medical Center, 1500 East Medical Center Drive, B1F245 Box 0022, Ann Arbor, Michigan 48109.
I $\mathrm{t}$ is well recognized that flow disturbances associated with changes in artery direction predisposc to atheroma formation ${ }^{1}$ and perhaps as many as $12 \%$ of all $\geq 50 \%$ stenoses occur in areas of vessel angulation $\geq 45^{\circ} .{ }^{2}$ Percutaneous transluminal coronary angioplasty (PTCA) of such stenoses is known to be associated with a heightened risk of ischemic complications, estimated to be 10 to $13 \%$ from available series, ${ }^{3,4}$ owing to an increased likelihood of arterial tearing (dissection). In fact, vessel angulation may contribute to as many as $44 \%$ of all major ischemic complications of coronary angioplasty. ${ }^{4}$ Analyses of clinical, anatomic and procedural variables associated with adverse PTCA outcome in this setting are not available. Therefore, 100 consecutive patients with PTCA performed at sites of $\geq 45^{\circ}$ angulation were extensively characterized to gain insight into how best to manage patients in this high-risk setting.

\section{METHODS}

Patient population: Every third coronary angioplasty performed in the setting of stable or unstable angina pectoris from March 1986 to June 1989 was reviewed by an experienced angiographer unaware of the outcome of the procedure to ascertain if the first angioplasty had been performed to a stenosis in which the inflated balloon extended across a $\geq 45^{\circ}$ arterial bend (present at end-diastole in a nonforeshortened view). ${ }^{4}$ One hundred of 444 patients met this criteria and formed the study population. The remaining 344 had a non-infarct and a nonangulated artery dilated during this time period, and the first stenosis dilated in this group comprised a control population.

Angioplasty procedure: The technique of angioplasty used has been described elsewhere. ${ }^{5}$ All patients were pretreated with oral aspirin 80 to $650 \mathrm{mg}$ daily for a minimum of 24 hours. After the administration of heparin (10,000 U intravenous bolus) and sometimes of nitroglycerin ( $0.4 \mathrm{mg}$ sublingual), preliminary angiography of the coronary artery to be dilated was performed in at least 2 projections. A dilatation balloon was chosen to have its inflated diameter approximate the normal lumen diameter at the site to be dilated. The balloon was positioned across the stenosis and inflated as many times as necessary to produce an optimal angiographic result. That result was angiographically documented in $\geq 1$ projection best showing the stenosis. Sheaths were usually removed 3 to 4 hours after completion of the procedure unless angiographic evidence of a coronary dissection or thrombus was seen, in which case an intravenous infusion of heparin (usually 1,000 U/hour ad- 
justed to the partial thromboplastin time) was administered overnight. After PTCA, the patients were taken to a postprocedure ward or to an intensive care unit, where they were monitored for a minimum of 18 to 24 hours. The patients were medicated with aspirin and a calcium antagonist, or nitrate preparation, or both. A 12-lead electrocardiogram was obtained immediately in the event of chest pain suggestive of ischemia, and, if ischemia was suspected, patients were usually returned for a cardiac catheterization and creatine kinase levels were followed. The patients were routinely discharged 1 to 2 days after PTCA.

Variables assessed: The following variables were assessed in the study group. Clinical variables were age, current smoking, gender and unstable angina pectoris. Anatomic variables were number of class B American College of Cardiology/American Heart Association (ACC/AHA) lesion characteristics, ${ }^{6}$ active stenosis angle, stenosis angle at end-diastole (Figure 1), asymmetric stenosis, bifurcation stenosis, calcification, chronic total occlusion, lesion length $\geq 50 \%$ (to the nearest $\mathrm{mm}$ ), multivessel disease, ostial stenosis, percent diameter stenosis before PTCA, roughened stenosis contour, thrombus and vessel tortuosity. Procedural variables were maximum balloon pressure, maximum balloon inflation duration, number of balloon inflations, maximum dilated balloon:artery ratio, experienced angioplasty operator ( $\geq 500$ procedures performed), use of dilatation balloon containing polyethylene terephthalate material (when multiple balloons were used, the balloon that completed an uncomplicated procedure, or that which was used immediately before vessel disruption or closure, was entered for analysis) and initial dilatation to $\leq 5 \mathrm{~atm}$. The definitions of these characteristics have been described previously.,7 The presence or absence of an angioplasty-induced tear (intimal disruptions $\leq 2$ $\mathrm{mm}$ that did not impair coronary flow were excluded) was noted in all study group patients and in a randomly selected subpopulation $(n=100)$ of the control group (Figure 2). All observations were made by an experienced angiographer unaware of clinical outcome. Dimensional measurements were made using a handheld caliper system and guide catheter calibration. The control population was characterized with regard to age, the presence of unstable angina, the vessel dilated and percent stenosis before PTCA.

Definitions of procedural success and complications: Procedural success was defined as reduction of the stenosis dilated to $<50 \%$ diameter stenosis and the absence of major ischemic complications through the time of hospital discharge. Major ischemic complications were defined as procedure-induced ischemia leading to death, bypass surgery or myocardial infarction (creatine kinase $>2$ times upper limit of normal with MB fraction $>4 \%$ ).

Statistical analysis: Data are expressed as mean \pm 1 standard deviation unless otherwise indicated. Chisquare analyses were used to test differences in categorical variables, whereas unpaired Student $t$ tests were used to assess differences in continuous variables. Mul- tiple stepwise logistic regression analyses were performed to determine clinical, angiographic and procedural correlates of outcome. The variable "angioplastyinduced tear" was considered a result of the procedure and therefore was not included in these analyses. All analyses were performed using SYSTAT software. ${ }^{8}$

\section{RESULTS}

Patient characteristics: Characteristics of the patients in the study population are listed in Table I. Patients in the study population did not differ from those having a nonangulated artery dilated in age ( $60 \pm 10$ vs $59 \pm 9$ years), incidence of unstable angina (42 vs $38 \%)$, percent diameter stenosis before PTCA $(73 \pm 11$ vs $69 \pm 12 \%$ ) or the distribution of vessels dilated (left anterior descending artery $=31 \%$, left circumflex artery $=31 \%$, right coronary artery $=31 \%$, saphenous vein bypass graft $=7 \%$ in the study group vs $33,28,33$ and $5 \%$, respectively, in the control group.)

Success and complications: Procedural success was achieved in only 70 of $100(70 \%)$ of the study patients compared with 306 of $344(89 \%)$ in the control group (p $<0.001$ ). Major ischemic complications occurred in 13 of $100(13 \%)$ of the study patients, compared with 12 of $344(3.5 \%)$ of the control patients $(\mathrm{p}<0.001)$. An angioplasty-induced tear was evident in $46 \%$ of the study group and $8 \%$ of the control group ( $<<0.001$ ), and the presence of a tear in the study group was correlated with the occurrence of a major ischemic event ( $20 \%$ in-

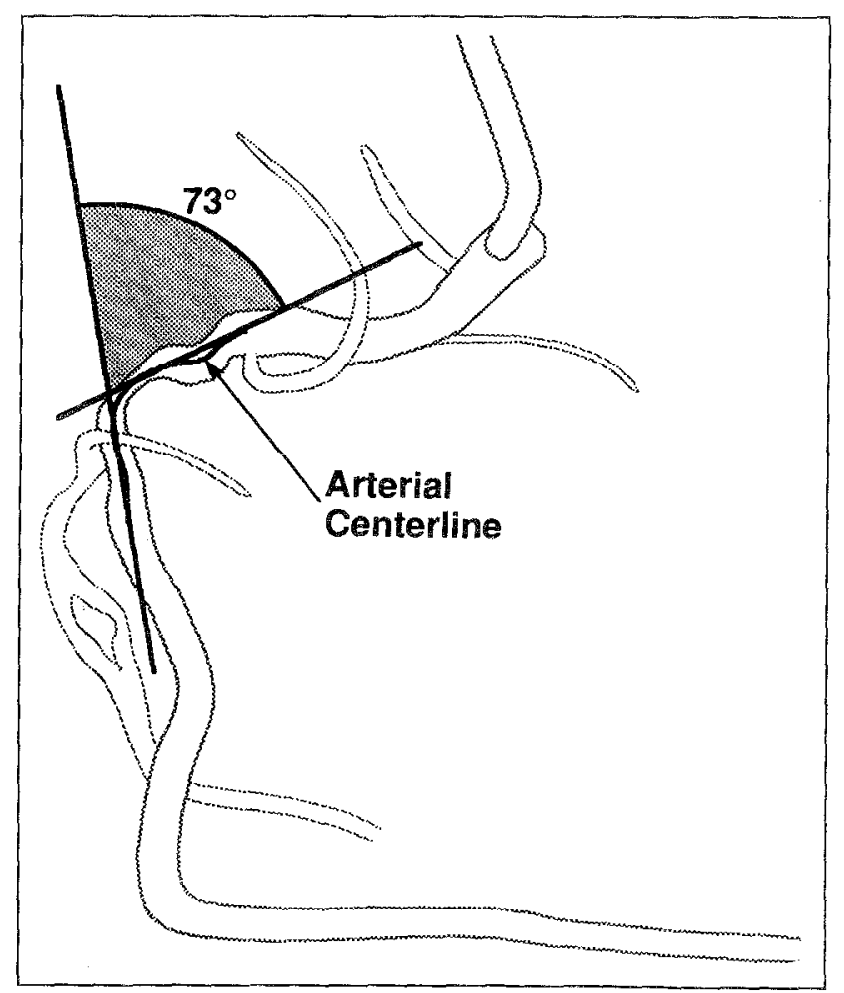

FIGURE 1. Method of angle measurement. In a nonforeshortened end-diastolic projection, the arterial centerline is drawn for a 20-mm segment centered on the stenosis. The anm gle between the proximal and distal segments is measured. 
cidence with a tear vs $7 \%$ incidence without a tear, $\mathrm{p}=$ 0.07 ). Reasons for procedural failure in the study population were the following: failure to dilate to a $<50 \%$ stenosis, discharged with medical therapy (11 patients, of whom 6 had a tear), angioplasty-induced ischemia requiring emergency bypass surgery $(n=8)$, failure to dilate to a $<50 \%$ stenosis with elective bypass surgery
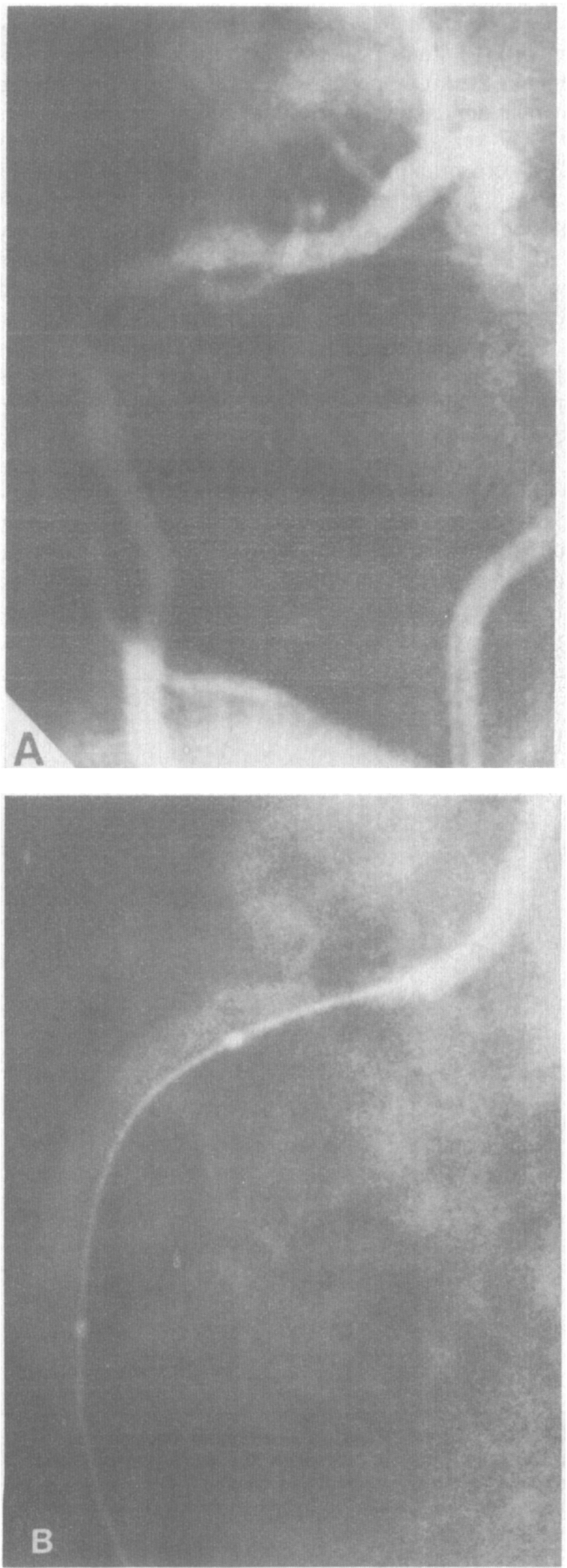

$(\mathrm{n}=4)$, failure to cross the stenosis with the dilatation balloon with subsequent elective bypass surgery $(n=3)$, failure to cross the stenosis with the guidewire with subsequent elective bypass surgery $(n=1)$, failure to cross the stenosis with the guidewire, and discharged treated with medical therapy ( $\mathrm{n}=1)$, angioplasty-induced ischemia leading to cardiac death $(n=1)$ and guidewireinduced dissection treated with elective bypass surgery $(\mathrm{n}=1)$.

Correlates of procedural success and major ischemic complications: The correlates of angioplasty success and complications arc listed in Tables II and III. The relation of the balloon dilatation catheter type to procedural outcome is listed in Table IV. Interestingly, highly angulated $\left(\geq 60^{\circ}\right)$ stenoses did not have a higher complication rate than did moderately angulated ( 45 to $\left.59^{\circ}\right)$ stenoses, 6 of $48(12.5 \%)$ versus 7 of $52(13.5 \%)$, respectively. Furthermore, deliberate balloon undersizing to balloon:artery ratios of 0.80 to 0.90 did not appear to reduce the complication rate compared with normal sizing (balloon:artery ratios 0.91 to 1.00 ); 3 of $23(13 \%)$ versus 3 of $45(7 \%)$ (difference not significant), respectively.

\section{DISCUSSION}

Despite advances in angioplasty technique, major ischemic complications continue to occur in 3 to $5 \%$ of

\section{FIGURE 2. A, left anterior oblique projection of a proximal $78 \%, 73^{\circ}$ right coronary artery stenosis in an 85-year-old man with class IV angina pectoris. $B$, balloon inflation using a polyvinylchloride material balloon. $\boldsymbol{C}$, the resultant propagated dissection (arrow). Emergency coronary artery bypass sur- gery was required.}

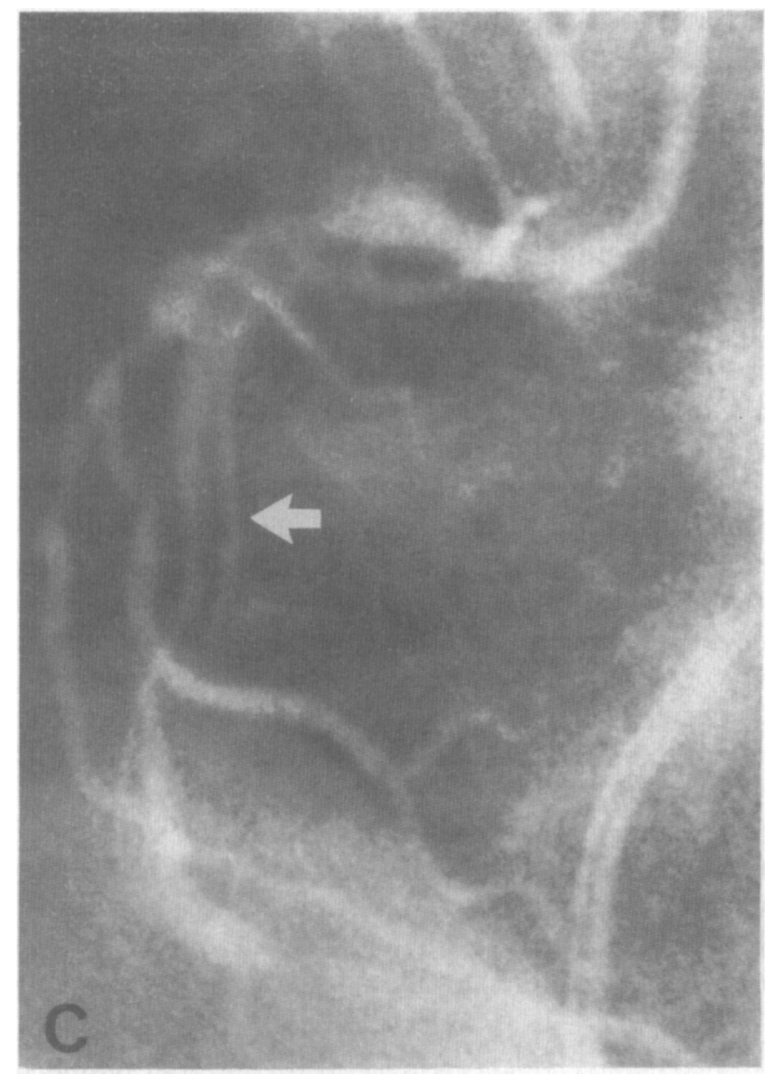


procedures. ${ }^{9}$ Factors associated with a lessened likelihood of success and a heightened risk of complications, among them dilatation at a bend, are well recognized. 34,6 This study was undertaken to better understand which instances of bend dilatation pose the highest risk, and, if possible, to suggest ways to lessen that risk.

The results show that PTCA to sites with a $\geq 45^{\circ}$ angulation was associated with only a $70 \%$ success rate and a $13 \%$ incidence of major ischemic complications, both considerably worse than the results with PTCA to nonangulated segments at this institution. The mechanism by which balloon inflation at a point of vessel angulation causes such a poor result appears to be due to arterial disruption from the balloon as it straightens, opens and tears the atherosclerotically fixed and rigid angulated arterial segment. Successful PTCA (Figure 3) was most closely correlated with use of polyethylene terephthalate balloons and absence of angiographically suggested thrombus (filling defect or staining), and major ischemic complications were significantly associated
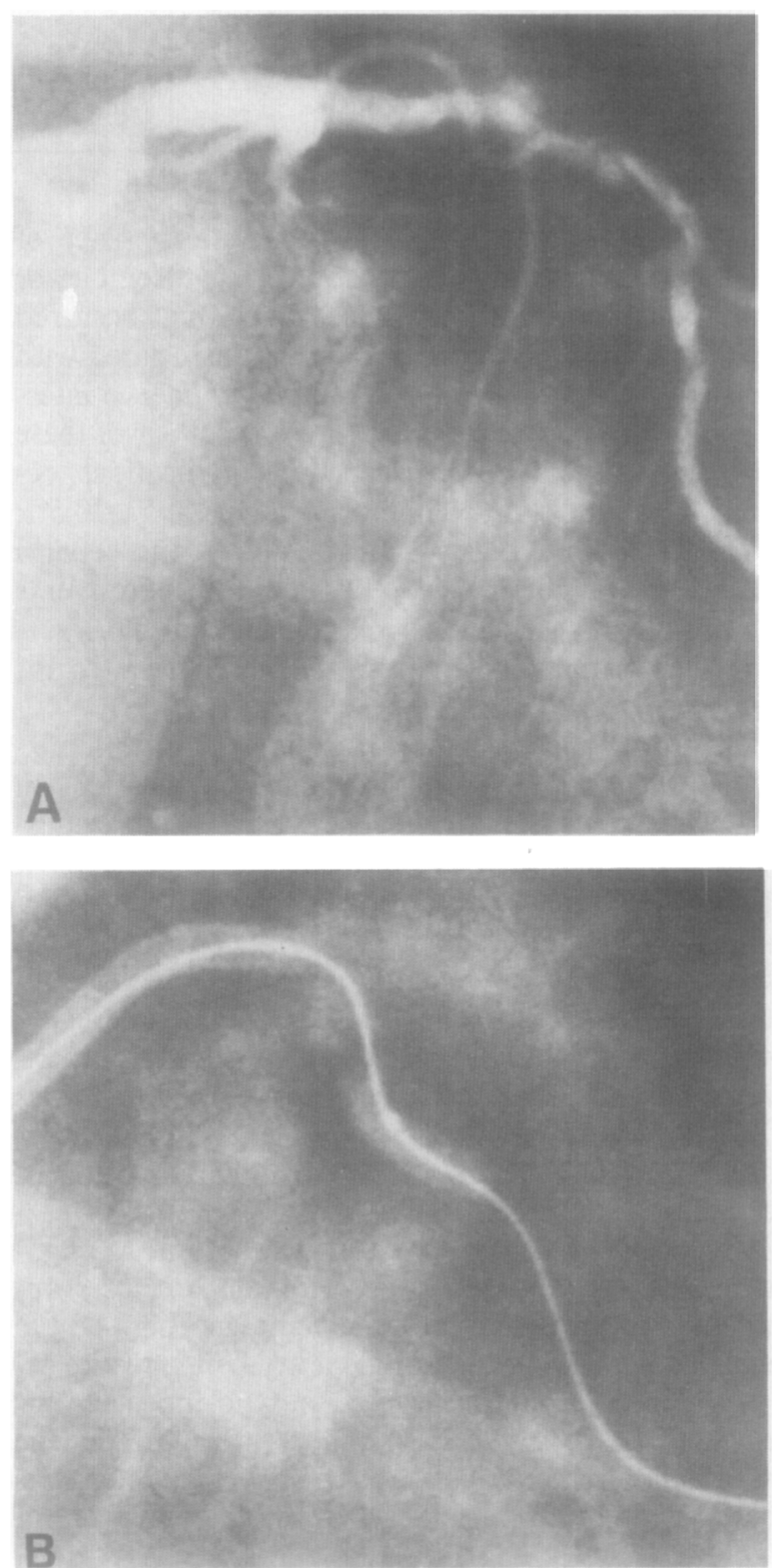

with advanced patient age, less experienced angioplasty operators, thrombus and longer lesions.

There have been no other comprehensive studies of the results of angioplasty for bend stenoses. Previous studies have consistently found PTCA risk to be associated with unstable angina pectoris, ${ }^{9,10}$ advanced

TABLE I Clinical, Angiographic and Procedural

Characteristics $(n=100)$

Clinical characteristics

Age (years)

Current smoking (\%)

Men (\%)

Unstable angina pectoris (\%)

Angiographic characteristics

Active stenosis angle (\%)

Bifurcation stenosis (\%)

Calcium (\%)

Chronic total occlusion (\%)

Eccentricity (\%)

Irregular contour (\%)

Multivessel disease (\%)

Ostial stcnosis (\%)

Percent diameter stenosis

Stenosis angle (degrees)

Stenosis length ( $\mathrm{mm}$ )

Thrombus (\%)

Tortuosity (\%)

Procedural characteristics

Balloon: artery ratio

Maximum inflation duration (sec)

Maximum inflation pressure (atm)

Number of inflations

Predilatation to $\leq 5$ atm (\%)

$60 \pm 10$

70

42

44

16

20

2

56

21

75

$69 \pm 12$

$62 \pm 13$

$5.2 \pm 4.1$

7

$0.94 \pm 0.13$

$103 \pm 46$

$8.0 \pm 1.7$

$3.8 \pm 2.0$

51

\begin{abstract}
FIGURE $3_{n}, A$, caudally angulated right anterior oblique prom jection of a subtotally occluded, $77^{\circ}$ (see $C$ ) left circumfiex coronary artery stenosis in a 60 -year-old man with class IV angina pectoris. $\boldsymbol{B}$, balloon inflation using a polyethylene terephthalate material balloon. $\boldsymbol{C}$, the resultant excellent angiographic result. There were no adverse clinical sequelae.
\end{abstract}

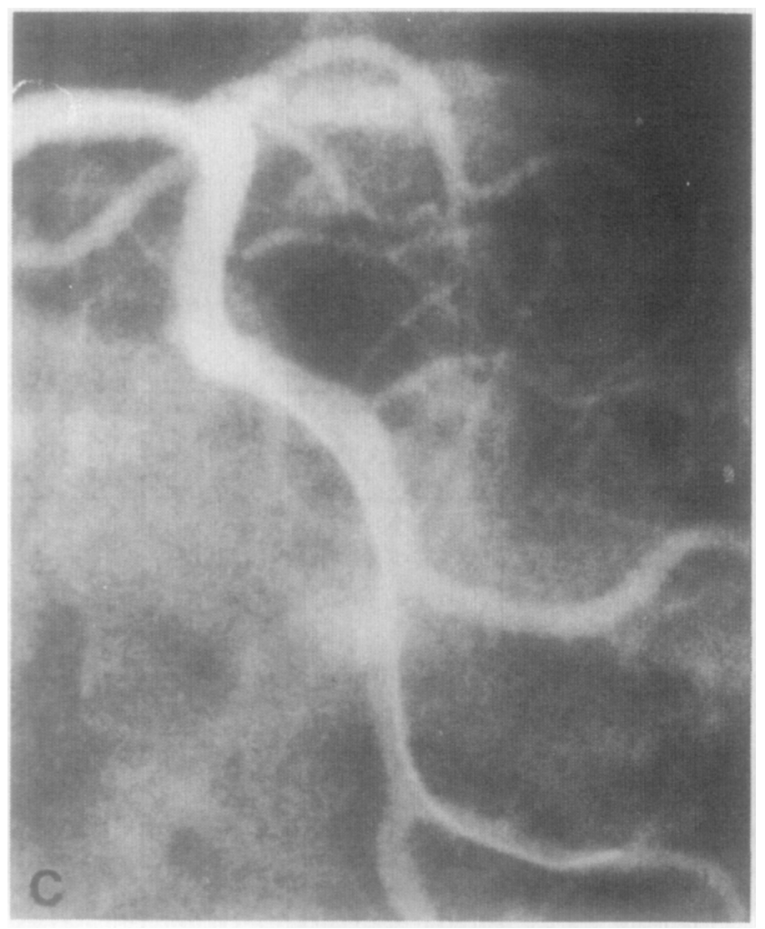




\begin{tabular}{|c|c|c|c|c|}
\hline Characteristic & $\begin{array}{l}\text { Success } \\
\text { Group }(n=70)\end{array}$ & $\begin{array}{l}\text { Failure } \\
\text { Group }(n=30)\end{array}$ & $\begin{array}{l}\text { Univariate } \\
\text { p Value }\end{array}$ & $\begin{array}{l}\text { Multivariate } \\
\text { p Value }\end{array}$ \\
\hline PET balloon material (\%) & 27.1 & 3.3 & $<0.001$ & 0.003 \\
\hline Thrombus (\%) & 2.9 & 17.2 & 0.057 & 0.039 \\
\hline Stenosis length $(\mathrm{mm})$ & $4.6 \pm 3.4$ & $6.5 \pm 5.3$ & 0.081 & 0.101 \\
\hline Roughened contour $(\%)$ & 14.5 & 36.7 & 0.028 & 0.104 \\
\hline Balloon: artery ratio $<0.8$ or $\geq 1.1(\%)$ & 25.7 & 46.7 & 0.052 & - \\
\hline Age (yrs) & $58 \pm 8$ & $62 \pm 11$ & 0.097 & - \\
\hline Number of ACC / AHA class B characteristics ${ }^{6}$ & $1.8 \pm 1.4$ & $2.2 \pm 0.8$ & 0.103 & $\sim$ \\
\hline
\end{tabular}

TABLE III Correlates of Major Ischemic Complications*

\begin{tabular}{|c|c|c|c|c|}
\hline Characteristics & $\begin{array}{l}\text { Complication } \\
\text { Group }(n=13)\end{array}$ & $\begin{array}{l}\text { No Complication } \\
\text { Group }(n=87)\end{array}$ & $\begin{array}{l}\text { Univariate } \\
\text { p Value }\end{array}$ & $\begin{array}{l}\text { Multivariate } \\
\text { p Value }\end{array}$ \\
\hline Age (yrs) & $66 \pm 10$ & $59 \pm 9$ & 0.011 & 0.034 \\
\hline Experienced PTCA operator (\%) & 61.5 & 80.5 & 0.19 & 0.048 \\
\hline Thrombus (\%) & 23.1 & 4.7 & 0.14 & 0.050 \\
\hline Stenosis length $(\mathrm{mm})$ & $7.7 \pm 6.4$ & $4.8 \pm 3.6$ & 0.11 & 0.052 \\
\hline Balloon: artery ratio $<0.8$ or $\geq 1.1(\%)$ & 53.8 & 28.7 & 0.10 & - \\
\hline PET balloon material $(\%)$ & 7.7 & 21.8 & 0.12 & - \\
\hline
\end{tabular}

\begin{tabular}{|c|c|c|c|}
\hline Catheter & $\begin{array}{l}\text { Balloon } \\
\text { Material }\end{array}$ & No.* & $\%$ Success \\
\hline Sci Med Skinny ${ }^{\top M}$ & PO & $22 / 31$ & 71.0 \\
\hline $\begin{array}{l}\text { ACS Simpson Ultra } \\
\text { Low Profile }\end{array}$ & $\mathrm{PE}$ & $10 / 14$ & 71.4 \\
\hline USCI®LS II & PVC & $6 / 12$ & 50.0 \\
\hline USC Profile Plus & PET & $10 / 11$ & 90.9 \\
\hline $\begin{array}{l}\text { ACS Hartzler } \\
\text { Micro }\end{array}$ & $\mathrm{PE}$ & $4 / 4$ & 100.0 \\
\hline USC1 Mini & PET & $4 / 4$ & 100.0 \\
\hline USC|® LPSI & PVC & $3 / 4$ & 75.0 \\
\hline $\begin{array}{l}\text { USCI® LPS II } \\
\text { Short }\end{array}$ & PVC & $3 / 3$ & 100.0 \\
\hline USC ${ }^{\circledast}$ Probe & PET & $3 / 3$ & 100.0 \\
\hline $\begin{array}{l}\text { ACS Simpson- } \\
\text { Robert }^{\text {TH }}\end{array}$ & $\mathrm{PE}$ & $2 / 2$ & 100.0 \\
\hline USCI Simplus & $P E$ & $2 / 2$ & 100.0 \\
\hline Sci Med Ace ${ }^{\text {tM }}$ & PO & $1 / 2$ & 50.0 \\
\hline ACS angled ${ }^{\top M}$ & $\mathrm{PE}$ & $0 / 1$ & 0.0 \\
\hline $\begin{array}{l}\text { ACS Simpson Uitra } \\
\text { Low Profile } \|^{T M}\end{array}$ & $\mathrm{PE}$ & $0 / 1$ & 0.0 \\
\hline \multicolumn{4}{|c|}{$\begin{array}{l}n=94 \text {, due to failure secondary to inability to cross with balloon in } 4 \text { patients and } \\
\text { wire-induced dissection in } 2 \text { patients. } \\
P E=\text { polyethylene; } P E T=\text { polyethylene terephthalate; } P O=\text { polyolefin; } P V C= \\
\text { polyvinylchloride. }\end{array}$} \\
\hline
\end{tabular}

age, ${ }^{11,12}$ longer lesions, ${ }^{4}$ thrombus, ${ }^{4,13}$ diffuse disease ${ }^{4}$ and balloon:artery ratios $>1.1 .^{7}$ One report has suggested that experienced operators have better results with complex stenoses than less experienced operators. ${ }^{14}$

This study adds to current knowledge by emphasizing the particular importance of patient age, concomitant thrombus, lesion length and operator experience in this setting, and for the first time suggests that the balloon material may be related to the likelihood of success or to complications of angioplasty. In the absence of high-risk characteristics (age $\geq 65$ years, thrombus or lesion length $\geq 10 \mathrm{~mm}$ ), major ischemic events occurred at a rate only slightly greater than that associated with nonbend stenoses ( 4 of $56=7 \%$; $95 \%$ confidence inter$\mathrm{val}=0$ to $14 \%$ ), whereas, in the presence of $\geq 1$ of these high-risk features, major ischemic complications occurred at a prohibitively high rate $(9$ of $44=20.5 \%$; $95 \%$ confidence interval $=14$ to $26 \%$ ). A long heparin infusion or the administration of thrombolytic agents may possibly be useful in decreasing the thrombus burden, which seems to be a covariable associated with adverse outcome. ${ }^{15}$

The importance of operator experience in minimizing the likelihood of major ischemic complications in high-risk patients has only been reported oncc previously in the voluminous body of angioplasty studies, yet it perhaps should not be surprising, given the known data on other surgical procedures. ${ }^{16}$ Highly experienced operators had a $55 \%$ lower rate of major ischemic complications (10 vs $23 \%$ ) in this series. This outcome could not be explained by differences between highly experienced and less experienced operators in the variables balloon:artery ratio, number of balloon inflations or number of class B ACC/AHA lesion characteristics of the stenosis dilated.

Angioplasty balloons that tend to conform to angulated arterial segments at high inflation pressures appear to improve procedural outcome in this setting. Bench studies in which an angioplasty balloon is inflated to $10 \mathrm{~atm}$ inside a standard acrylic model artery formed to a $90^{\circ}$ angle have shown that polyethylene terephthalate material balloons deform (straighten) the model artery by 36 to $43^{\circ}$, whereas balloons made of 
polyethylene or polyolefin cause deflections of 57 to $63^{\circ}$ (Mclntyre J, personal communication, 1989), possibly causing less straightening stress and propensity toward medial disruption (tearing). The low profile of polyethylene terephthalate balloons may also be useful in this setting. However, differing thicknesses of polyethylene terephthalate material balloons are currently under evaluation, and the results reported herein may not apply to all such balloons.

This study is limited by the relatively few number of cases studied and by the multiple statistical comparisons made. As such, one must not conclude that balloon composition alone defines the likelihood of procedural success for a given balloon and that high success rates cannot be achieved with equipment evaluated in small numbers in this study. Furthermore, subset analysis may be inconclusive (for example, the question as to whether polyethylene terephthalate balloons used in high-risk bend lesions would result in an acceptable complication rate is unanswered-with 1 of $9(11 \%)$ [0 to $33 \%$; $95 \%$ confidence intervals $]$ having a major ischemic complication), and the likelihood of a statistical type II error is increased. In addition, subjectivity of assessment of arterial morphology must be recognized. ${ }^{2,4}$ All evaluations in this study were performed by a single observer. Previous studies have reported, however, an interobserver variability of $12 \%$ for bend stenoses. $^{4}$

\section{REFERENCES}

1. Zarins CK, Giddens DP, Bharadvaj BK, Sottiurai VS, Mabon RF, Galgov S. Carotid bifurcation atherosclerosis: quantitative correlation of plaque localization with flow velocity profiles and wall shear stress. Circ Res 1983;53:502-514. 2. Ellis S, Alderman EL, Cain K, Wright A, Bourassa M, Fisher L, and the Participants of the Coronary Artery Surgery Study (CASS). Morphology of left anterior descending coronary territory lesions as a predictor of anterior myocardial infarction: a CASS registry study. J Am Coll Cardiol 1989;13:1481-1491. 3. Ischinger T, Gruentzig AR, Meier B, Galan K. Coronary dissection and tutal coronary occlusion associated with percutaneous transluminal coronary angio- plasty: significance of initial angiographic morphology of coronary stenoses. Circulation 1986;74:1371-1378.

4. Ellis SG, Roubin GS, King SB, Douglas JS, Wcintraub WS, Thomas RG, Cox WR. Angiographic and clinical predictors of acute closure after native vessel coronary angioplasty. Circulation 1988;77:372-379.

5. Ellis SG, Roubin GS, King SB, Douglas IS, Shaw RE, Stertzer SH, Myler RK In-hospital cardiac mortality after acute closure after coronary angioplasty: analysis of risk factors from 8,207 procedures. $J$ Am Coll Cardiol 1988;11:211-216 6. Ryan TJ, Faxon DP, Gunnar RM, Kennedy JW, King SB, Loop FD, Peterson KL, Reeves TJ, Williams DO, Winters WL, Fisch C, DeSanctis RW, Dodge HT, Reeves TJ, Weinberg SL. Guidelines for percutaneous transluminal coronary angioplasty: a report of the American College of Cardiology/American Heart Association Task Force on Assessment of Diagnostic and Therapeutic Cardiovascular Procedures (Subcommittee on Percutaneous Transluminal Coronary Angioplasty). J Am Coll Cardiol 1988;12:529-545.

7. Roubin GS, Douglas JS, King SB, Lin S, Hutchison N, Thomas RG, Gruentzig A. Influence of balloon size on initial success, acute complications, and restenosis after percutaneous transluminal coronary angioplasty. Circulation 1988:78:557-565.

8. The System for Statistics. Evanston, Illinois: SYSTAT, 1986.

9. Holmes DR Jr, Holubkov R, Vlicstra RE, Kelsey SF, Reeder GS, Dorros G Williams DO, Cowley MJ, Faxon DP, Kent KM, Bentivoglio LG, Detre K, and the Co-Investigators of the National Heart, Lung, and Blood Institute Percutaneous Transluminal Coronary Angioplasty Registry. Comparison of complications during percutaneous transluminal coronary angioplasty from 1977 to 1981 and from 1985 to 1986: the National Heart, Lung, and Blood Institute Percutaneous Transluminal Coronary Angioplasty Registry. J Am Coll Cardiol 1988;12:11491155 .

10. de Feyter PJ, Suryapranata H, Scrruys PW, Beatt K, Van Domburg R, Van den Brand M, Tijssen JJ, Azar AJ, Hugenholtz PG. Coronary angioplasty for unstable angina: immediate and late results in 200 consecutive patients with identification of risk factors for unfavorable early and late outcome. $J \mathrm{Am}$ Coll Cardiol 1988:12:324-333.

11. Simpfendorfer C, Raymond R, Schraider J, Badhwar K, Dorosti K, Franco I, Hollman J, Whitlow P. Early and long-term results of percutaneous transluminal coronary angioplasty in patients 70 ycars of age and older with angina pectoris. Am J Cardiol 1988;62:959-961.

12. Kern MJ, Deligonul U, Galan K, Zelman R, Gabliani G, Bell ST, Bodet J, Naunheim K, Vandormael M. Percutaneous transluminal coronary angioplasty in octogenarians. Am J Cardiol 1988;61:457-458.

13. Sugrue DD, Holmes DR Jr, Smith HC, Reeder GS, Lane GE, Vlietstra RE, Bresnahan JS, Hammes LN, Piehler JM. Coronary artery thrombus as a risk factor for acute vessel occlusion during percutaneous transluminal coronary angioplasty: improving results. Br Heart $J$ 1986;56:62-66.

14. Hamad N, Pichard AD, Lyle HRP, Lindsay J. Results of percutaneous transluminal coronary angioplasty by multiple, relatively low frequency opcrators: 1986-1987 experience. Am J Cardiol 1988;61:1229-1231.

15. Douglas JS, Lutz JF, Clements SD, Robinson RH, Roubin GS, Lembo NJ, King SB. Therapy of large intracoronary thrombi in candidates for percutaneous transluminal coronary angioplasty (abstr). $J$ Am Coll Cardiol 1988;11:238A. 16. Hannen EL, O'Donnel JF, Kilburn H, Bernard HR, Yazici A. Investigation of the relationship between volume and nor tality for surgical procedures per formed in New York State hospitals. JAMA 1989;262:503-510 